\title{
A MISSÃO DO ESCRITOR E O SISTEMA LITERÁRIO NO SÉCULO XIX: MÉXICO (GUILLERMO PRIETO) E O BRASIL (JOSÉ DE ALENCAR) NA CRIAÇÃO DE UM ESTADO NACIONAL A PARTIR DA LITERATURA
}

\author{
Francisco Lima Baca ${ }^{109}$
}

RESUMO: $O$ artigo desenvolve uma comparação entre dois projetos estéticos no Brasil e no México no século XIX. No caso de Guillermo Prieto, o nomeado costumbrismo é a representação literária dos costumes sociais que criam uma identidade, uma vez que o conceito "missão do escritor" tenha um relacionamento forte com a concepção de um Estado Nacional. Esse projeto literário desenvolvido no México tem relação com o projeto de José de Alencar, já que o escritor vai desenvolver uma proposta narrativa, na qual, a Literatura Brasileira terá sua identidade estética. A relação entre os dois projetos literários estabelece um encontro entre as duas propostas narrativas e dois projetos nacionais, nos quais a Literatura é uma ferramenta para desenvolver uma identidade nacional no caso mexicano e brasileiro no século XIX.

Palavras-chave: Missão do escritor; nação; identidade nacional; projeto literário.

ABSTRACT: The presente work develop one comparation betwen two aesthetics projects in Brasil and Mexico in the XIX century. In the case of Guillermo Prieto, the "Costumbrismo" its a literary representation of social custos who develop one identity, and the concepto of "misión del escritor" as a stronger relation whit the idea of National State. This literary Project as relation whit the Project of José de Alencar because this writer develop one narrative propos where the brazilian literature has a aesthetical identity. The relation betwen this two literary projects has one way to undestand two narrative propositions and two national projects where the literature its a importante elemento for develop one national identity in the mexican and brazilian culrure in the XIX century.

Keywords: Nation; national identity; Literary Project; writer mission.

${ }^{109}$ Pós-doutorando em Teoria e História Literária. Instituto de Estudos da Linguagem IEL. Universidade Estadual de Campinas UNICAMP. 
Roger Picard, na sua obra, El romanticismo social, determina a função do romance e do romancista no capítulo intitulado "Los novelistas sociales". Para o autor, o romancista estabelece o que será definido como "noções de espírito" e "ideias a favor da ficção", a partir de três categorias: a) o pensamento; b) a filosofia e c) o público leitor:

La novela se presenta, pues, como un mediador poderoso entre los pensamientos de una época, las filosofías en marcha, y la multitud que no tiene acceso directo a ellos y que no lee más que obras de ficción (PICARD, 2005, p. $158)^{110}$.

O pensamento, a filosofia e o público leitor de obras de ficção estabelecem uma relação entre o romancista, como sujeito social e político, com a obra da arte literária, onde a ficção configura o mundo social que o autor representa a partir da sua própria visão de mundo. Nessa perspectiva ou horizonte, ${ }^{111}$ o romancista cria, em concordância com a análise de Roger Picard, dois tipos de romance: a) os descritivos e b) os ideológicos, assim definidos; nos romances descritivos, o romancista não só faz ênfase na psicologia dos personagens, além disso, desenvolve uma representação dos universos sociais dos mesmos, e nos romances ideológicos, o personagem e seu entorno são uma expressão de conceitos morais, além de uma crítica às instituições e uma exaltação das doutrinas reformadoras da sociedade:

la novela aborda los temas sociales más variados; se convierte en escuela de historia, de sociología y de moral; la novela es la forma preferida por los autores que, estando dotados de una imaginación narrativa, tienen doctrinas que desarrollar o una propaganda que hacer (PICARD, 2005, p. 159) ${ }^{112}$.

\footnotetext{
${ }^{110}$ A novela vai se apresentar, pois, como um mediador poderoso entre os pensamentos de uma época, as filosofias em andamento, e a multidão que não tem acesso direito a eles e que não lê mais que obras de ficção (PICARD, 2005, p. 158)

${ }^{111}$ A categoria nomeada "horizonte" é desenvolvida pelo filósofo espanhol José Ortega y Gasset na sua obra: La deshumanización del arte, nela o autor vai definir que o horizonte do artista é a perspectiva do homem que tá olhando numa janela e o olhar dele vai se definir pela posição do mesmo na frente dum objeto ou coisa que ele percebe.

112 a novela aborda os temas sociais mais variados; vai se tornar em escola de historia, de sociologia e de moral; a novela é a forma preferida pelos autores que, estando dotados de uma
} 
O romancista social, a partir da ficção, vai ser o ideólogo de um projeto de estado, onde a noção de espírito, o retrato ou a pintura de caracteres e o mundo social representado definirão uma poética social e estética, política e ideológica, com normas sociais e morais que definem a um cidadão ideal, ou vai desvelar as carências que impedem aos indivíduos representados a possibilidade de serem assim mesmo. O romancista vai cumprir uma missão, a de representar o mundo social, cultural, político e ideológico nas obras literárias, e no caso específico de Guillermo Prieto, escritor mexicano, e José de Alencar, brasileiro, a partir dos seus conceitos de literatura, pelo qual, é importante responder às seguintes questões: Qual é a missão do romancista mexicano e brasileiro no século XIX? Qual é o ponto de encontro de dois romancistas com olhares diferentes?

Nos estudos introdutórios do livro: La novela corta en el primer romanticismo mexicano, Jorge Ruedas de la Serna e Celia Miranda Cárebes coincidem em assinalar a função da literatura como parte de um projeto de estado que vai acontecer na primeira metade do século XIX, o qual tem uma influência do romantismo como modelo poético e estético. Esse romantismo vai ter um caráter político, já que, para os romancistas, a literatura será o meio para criar o primeiro projeto de identidade nacional, onde o escritor e a literatura vão ter um papel ou uma missão, que pode ser definida pelos seguintes $\operatorname{pontos}^{113}$ : a) a reflexão e a autorreflexão, uma maneira pela qual o romancista mexicano vai se posicionar diante de um novo projeto de estado; $\mathrm{b}$ ) o fato de mostrar a utilidade da literatura como uma forma de melhorar a sociedade, ou seja, a literatura, num sentido prático ou pragmático, é uma maneira de representar modelos de conduta, ética, moral e política com a ficção literária; c) a depuração dos costumes, que faz referência ao fato de que, o romancista, ao fazer uma reflexão e dar à literatura uma utilidade. A depuração dos costumes, porém, é uma melhora da sociedade com a representação dos costumes nacionais; d) o fortalecimento da moral pública, ou seja, a literatura ao representar um modelo de condutas ideais é uma ferramenta que permite a construção política de uma moral pública, além da representação de um modelo de

imaginação narrativa, tem doutrinas que desenvolver o uma propaganda que fazer (PICARD, 2005, p. 159).

${ }^{113}$ As categorias desenvolvidas são as reflexões da "Presentación", de Jorge Ruedas de la Serna, do livro La misión del escritor. Ensayos mexicanos delsiglo XIX. 
conduta do cidadão moderno; e) a revalorização do patrimônio, que é o fato de representar costumes, usos, normas de conduta, um modelo histórico, um modelo de identidade que vai servir para entender a história de um cidadão integrado numa nova república moderna e f) $o$ fortalecimento da consciência nacional, que é a categoria final que fecha todas as definidas anteriormente para assinalar a missão do escritor na literatura do século XIX, no México, com a ficção dos costumes, modelos de patrimônio nacional, condutas éticas, morais e civis, e com a forma ou modelo que o romancista romântico vai usar nas suas obras.

No livro: La misión del escritor. Ensayos mexicanos del siglo XIX, Pablo Mora ao fazer uma análise da obra de Guillermo Prieto ${ }^{114}$ questionará o seguinte:

¿hasta qué punto esta preocupación por reconocer los productos literarios, la escritura de la historia literaria de México y la persistencia de los proyectos editoriales frustrados o no de libros y revistas - a lo largo de varios años (1826 - 1867) no significaron la posibilidad de mantener viva una imagen cultural - y en este sentido un proyecto de nación - que se verá consumada en los años de la República Restaurada? (MORA, 1996, p. 105) ${ }^{115}$.

Essa questão vai envolver a concepção de um projeto de estado, onde a arte serve para desenvolver normas sociais, culturais e politicas e, no caso de Guillermo Prieto, vai ter um relacionamento com a representação dos costumes da sociedade mexicana no século XIX.

A literatura, para Guillermo Prieto, tem a seguinte função:

\footnotetext{
114 O "costumbrista" Guillermo Prieto, vai nascer no ano de 1818, ele, além de outros romancistas e politicos, vai ser parte da nomeada "Academia de Letrán”, a qual teve uma influencia importante na criação do projeto nacional mexicano no século XIX. Guillermo Prieto, concordando com as ideias de José Luis Martinez, vai ser parte de uma primeira geração de intelectuais que nos anos de 1836 a 1867 vai desenvolver uma arte "propriamente mexicana" ao falar das paisagens e dos costumes de uma nova nação.

115 até que ponto esta preocupação por reconhecer os produtos literários, a escritura da historia literária de México e a persistência dos projetos editoriais - frustrados ou não de livros e revistas - num longo periodo de tempo (1826 - 1867) não significaram a possibilidade de manter viva uma imagem cultural - e nesse sentido um projeto de nação - que se verá consumado nos anos da República Restaurada? (MORA, 1996, p. 105).
} 
porque la literatura de un pueblo no puede ser obra de un hombre, ni de determinado número de años, y en las sociedades modernas, que por los vehículos de la imprenta, el comercio y otros, hay reciprocidad de ideas, para que una literatura adquiera un tipo especial, es forzoso que las producciones de otros países, se modifiquen, se aclimaten, y por una sucesión de trabajos, se transformen y conviertan en literatura característica de un pueblo (PRIETO, 1996, p. $119)^{116}$.

A literatura é a semente de uma sociedade, de um projeto político de nação, onde a representação dos alimentos, das roupas, das raças, da religião faz com que o leitor sinta uma relação com as coisas, com as pessoas e com os objetos que o autor concebe na obra literária. No caso particular de Guillermo Prieto, os chamados "Cuadros de costumbres" ou “Costumbrismo", serão essa representação quotidiana da sociedade, da vida social que, na primeira metade do século XIX, vai ser o primeiro olhar de um projeto nacional depois da luta de independência. Ele estará presente nas intituladas "Academias", particularmente da Academia de Letrán, primeira expressão de uma educação e de uma literatura independente.

Alicia Perales Ojeda no seu livro: Las Asociaciones Literarias Mexicanas, Tomos I y II, vai desenvolver uma reflexão da composição geográfica e política no México no século XIX e, ao falar da formação das "asociaciones literarias" na Europa, vai assinalar a importância das mesmas no México. No capítulo "Asociaciones de la corriente literária del romanticismo (1836 -1867)", a autora vai dizer que uma das etapas mais importantes na formação da literatura nacional, no México, é a que vai acontecer nas décadas de 1830 e 1860, nas quais, La Academia de San Juan

\footnotetext{
${ }^{116}$ porque a literatura de um povo não pode ser obra de um homem, nem de um determinado número de anos, e nas sociedades modernas, que pelos veiculos da imprensa, o comercio e outros, há reciprocidade de ideias, para que uma literatura consiga ter um tipo especial, é forçoso que as produções de outros paises, se modifiquem, se aclimatem, e por uma sucessão de trabalhos, se transformem e convertam em literatura característica de um povo (PRIETO, 1996, p. 119).
} 
de Letrán, vai cumprir um papel fundamental no nascimento de uma nacionalidade mexicana:

La fundación de la Academia de San Juan de Letrán tuvo lugar en una etapa verdaderamente tormentosa de la historia de México. Desde la consumación de la Independencia al triunfo de la República en 1867, México sufrió incontables revoluciones, dos invasiones extranjeras y numerosos e inestables gobiernos que, buscando contrarios propósitos, ocasionaron irreparables daños. Esa dualidad de intereses, surgida del deseo de conservar por una parte la tradición y por otra de acabar con ella, tuvo como lamentable resultado las luchas fratricidas que asolaron por largos años al país (PERALES, 2000, p. 74) $)^{117}$.

Num país onde começa a consolidação de um projeto de estado moderno, as chamadas "Asociaciones" e "Academias" vão cumprir um papel fundamental, o de formar um projeto de identidade no qual a literatura vai desenvolver a função de representar valores éticos, morais e civis a partir da poesia, da narrativa e das reflexões que os romancistas vão fazer da realidade nacional.

Para compreender de uma melhor maneira a função das academias no México é importante refletir o seguinte: no capitulo "El aprendizaje de la libertad 1810 - 1836", do livro La Expresión Nacional José Luis Martínez, ao falar das primeiras expressões literárias de uma jovem nação independente, vai definir o que é um "cambio de inspiración”, o qual é um novo olhar onde os heróis da independência mexicana vão se tornar figuras sublimes e poetizadas a partir dos seus atos. De igual maneira, "lo nativo" e o que autor apresenta como "el pueblo" no capítulo citado, são duas categorias que também vão configurar uma nova concepção literária ao serem considerados como elementos substanciais de um jovem projeto de estado, onde o regional vai ser uma característica de valor universal:

\footnotetext{
${ }^{117}$ A fundação da Academia de San Juan de Letrán aconteceu numa etapa verdadeiramente tormentosa da historia do México. Desde a consumação da Independência até o triunfo da República em 1867, México sofreu incontáveis revoluções, duas invasões estrangeiras e numerosos e instáveis governos que, procurando contrários propósitos, ocasionaram irreparáveis danos. Essa dualidade de interesses, surgida do desejo de conservar por uma parte a tradição e por outra de acabar com ela, teve como lamentável resultado as lutas fratricidas que devastaram por longos anos ao pais (PERALES, 2000, p. 74).
} 
El cambio era, en efecto, radical; era el paso de una literatura amanerada e inocua a esta manera de dar voz al pueblo y escribir como él hablaba (MARTÍNEZ, 1993, p. 33) ${ }^{118}$.

$\mathrm{Na}$ citação anterior, o autor, ao falar de um escritor mexicano chamado Joaquín Fernández de Lizardi $\left(1776\right.$ - 1827) ${ }^{119}$ vai articular a ideia de um "aprendizaje de la libertad" na qual a arte, e particularmente a literatura, é a expressão de um caráter nacional.

O romantismo vai ser uma nova via no processo da literatura no México no século XIX, o qual, além de um "sentimentalismo, melancolía e introspección" de que fala José Luis Martínez, vai definir, ao mesmo tempo, uma "independencia" e um "viento de rebeldia". O costumbrismo ${ }^{120}$ de

${ }^{118} \mathrm{O}$ cambio era, em efeito, radical; era o passo de uma literatura amaneirada e inócua a esta maneira de dar voz ao povo e escrever como ele falava (MARTÍNEZ, 1993, p. 33).

${ }^{119}$ José Joaquin Fernández de Lizardi é considerado um dos mais importantes romancistas no México no século XIX pelo fato de desenvolver uma literatura nacional e criar uma novela chamada: El periquillo sarniento, na qual, o escritor vai criar o primer personagem com uma lingua popular e com caracteristicas que vão definir uma cultura mexicana.

120 O "cuadro de costumbres", concordando com a análise que desenvolve Jorge Ruedas de la Serna no seu artigo: "Cuando pinto no retrato" é uma ficção poética onde há uma imitação com ações, cores, imagens, além de homens que tem um agir em relação ao vício e a virtude. "Más, puesto que los que imitan imitan a hombres que actúan, y éstos necesariamente serán esforzados o de baja calidad (los caracteres, en efecto, casi siempre se reducen a éstos solos, pues todos sobresalen, en cuanto al carácter, o por el vicio o por la virtud), o bien los hacen mejores que solemos ser nosotros, o bien peores o incluso iguales, lo mismo que los pintores." (ARISTÓTELES, 1999, p. 131). Para o "costumbrismo" as ações dos personagens são parte de uma representação dramática como se fossem a tela de uma pintura que faz ressaltar o caráter dos mesmos. Os "cuadros de costumbres" estabelecem uma relação com o que "deveria ser" já que neles o escritor desenvolve um pacto e um compromisso que tem um relacionamento com sua sociedade e com a arte que o escritor desenvolve. Ao igual que Aristóteles, para Ignacio Luzán, a poética deve ter um uma representação da realidade com a imagem: "Paréceme pues, que la verosimilitud no es otra cosa sino una imitación, una pintura, una copia bien sacada de las cosas, según son en nuestra opinión, de la cual pende la verosimilitud; de manera que todo lo que es conforme a nuestras opiniones (sean estas erradas o verdaderas) es para nosotros verosimil, y todo lo que repugna a las opiniones que de las cosas hemos concebido es inverosimil. Será pues verosimil todo lo que es creible, siendo creible todo lo que es conforme a nuestras opiniones" (LUZÁN, 1974, p. 150). O que Ignacio Luzán define como "costumbrismo" vai ser um retrato da realidade, onde vai se criar uma imagem real do mundo que o autor representa com uma perspectiva social, onde a imagem, o "cuadro de costumbres", precisa ser verosimil, deve dar ao leitor uma ideia clara e certa da realidade, deve estabelecer um ordem na descrição, com a verossimilitude como ferramenta 
Guillermo Prieto, além de buscar uma "independencia" e um "viento de rebeldia”, vai procurar representar a sociedade urbana no México, desenvolvendo uma crítica social e política das distintas classes sociais que formam parte da mesma. No livro nomeado: Cuadros de costumbres I, tem uma seleção de documentos escritos nos anos de 1840 e 1842 intitulados: "Cuadros de costumbres" 121 , nos quais se fala, por exemplo, da representação da cidade do México:

México, la hija más opulenta y gentil del Nuevo Mundo, la joven caprichosa y desgraciada; inquieta y desidiosa; cortejada por la ambición extranjera y envilecida por la criminal apatía de sus hijos; pues ved hoy domingo a esta capital, como quien dice, vestida de limpio, religiosa y preocupada, galana y ridícula; presentando a todos los ojos su conjunto indescriptible; pero con no sé qué de risueño y bondadoso. Su cielo, su única positiva riqueza, contra la cual no conspira la amistad extranjera y el furor "empleomático", ha brillado con la luz que anuncia descanso al perezoso oficinista, y tormento al breve pie de la joven presumida, y a la frágil cintura del almibarado plagio de los elegantes de París (PRIETO, 1993, p. 39) ${ }^{122}$.

A cidade do México que descreve Guillermo Prieto no seu artigo é comparada com uma "joven caprichosa" onde as questões religiosas estão envolvidas com uma sociedade que gosta da cultura estrangeira, francesa particularmente, e com a moral de uma sociedade conservadora e católica que procura a modernidade ainda com a contradição do seu próprio

para desenvolver seus juizos e ideias; porém o autor, o criador, deve estabelecer uma relação entre a realidade e a obra da arte literária com uma criação poética verosímil e ficcional com um sentido dialético na própria obra da arte.

${ }^{121} \mathrm{Um}$ dos livros mais conhecidos de Guillermo Prieto se titula: Memorias de mis tempos, nele o autor, ao falar da sua vida pessoal, faz uma reflexão das questões quotidianas que envolvem a politica e a sociedade mexicana depois do periodo da Independência no México.

${ }^{122}$ México a filha mais opulenta e gentil do Novo Mundo, a moça caprichosa e desgraçada; inquieta e negligente; cortejada pela ambição estrangeira e envilecida pela criminal apatia dos seus filhos; pois olhem hoje domingo a esta capital, como dizem, vestida e limpa, religiosa e preocupada, enfeitada e ridicula; presentando a todos os olhos seu conjunto indescritivel; mas com não sei o que de sorridente e bondoso. Seu céu, sua única positiva riqueza, contra a qual não conspira a amizade estrangeira e o furor "empleomático", há brilhado com a luz que anuncia o descanso ao preguiçoso escrevente, e tormento ao breve pê da moça presumida, e á frágil cintura de doce plagio dos elegantes de Paris (PRIETO, 1993, p. 39). 
contexto social e religioso. Por exemplo, no artigo "Costumbres mexicanas II. Posadas", publicado no ano de 1841, Guillermo Prieto faz a descrição das festas que são celebradas no México antes do Natal e que são nomeadas "posadas". Na descrição de Guillermo Prieto, a cidade faz parte dessa mesma festa, onde a religiosidade tem um relacionamento forte com os costumes, as roupas e até os mesmos alimentos que são descritos no artigo do escritor:

Ya no a la luz fulgente del fogón de ocote se descubre de esquina en esquina el fresco puesto de chía con su vestido rústico de alfalfa, orlado de amapolas y rosas, con su simétrica cenefa de las mismas flores, en donde el chícharo y la retama exhalan su perfume [...] Más airoso, más desenvuelto con un extremo de la sábana debajo del brazo, el talle más gentil y la voz más limpia y entonada, se anuncia la tortilla de cuajada: los dulceros y otros bichos pertenecen a todas las estaciones. Voyme desviando en inútiles digresiones, lo conozco; pero me es imposible remediarlo: sigo mi recuento como mejor pudiere, que no quiero ahora poner en prensa mi ingenio, ya que tantas veces la dura necesidad me obligó a sujetarlo a un martirio doloroso. [...] Los hachones de la esquina descubren sendos canastos, de tostados cacahuetes, jícamas, naranjas, y el coco abrigado con las pachonas hebras que lo cubren: atizando el fogón grita el dueño que es el Abraham de la casi desnuda familia que lo rodea, con voz de bassoassoluto: "al buen coco fresco, cacahuete tostado de horno” (PRIETO, 1993, p. 48-49) ${ }^{123}$.

\footnotetext{
123 Já não a luz fulgente da fogueira de madeira se descobre de esquina em esquina o fresco barraquinho de chía com seu vestido rústico de alfafa, orlado de amapolas e rosas, com seu simétrico debrum das mesmas flores, onde a ervilha e a retama exalam seu perfume [...] Mais airoso, mais desenvolvido com um extremo do lenço embaixo do braço, a cintura mais gentil e a voz mais limpa e entonada, se anuncia a tortilla de cuajada: os vendedores de doces e outros bichos são parte de todas as estações. Vou me desviando em inúteis digressões, eu reconheço; mas não me é possivel remediar isso: prossigo o meu reconto como melhor posso fazer, que não quero agora pôr em prensa meu engenho, já que tantas vezes a dura necessidade me força a sujeitar o mesmo a um martirio doloroso. As tochas da esquina descobrem enormes cestos, de amendoim torrado, jicamas, laranjas e o coco abrigado com os veludos fios que o cobrem: avivando a fogueira grita o dono que é o Abraham da quase nua familia que o rodeia,
} 
Os alimentos que são descritos no artigo do autor, além das roupas e das falas das pessoas que vendem os mesmos, fazem parte de uma representação de "costumbres mexicanas" que não tem comparação com outra cultura ou sociedade e que, ainda com as suas contradições, fazem com que o mexicano seja mexicano nos mesmos "cuadros" que o autor descreve.

O costumbrismo, além de ter o que José Luis Martinez define como um "viento de rebeldía" é uma procura constante de originalidade, descreve as coisas que fazem com que o mexicano seja mexicano num período de tempo onde é preciso construir uma nação e um projeto de estado, onde a questão da missão do escritor é fundamental e, porém, os costumes, a descrição dos espaços, das questões religiosas, da própria cidade como um personagem a mais, são fundamentais no processo narrativo:

De las casa de la vecindad salen cánticos tumultuosos en coro, que se mezclan con el ruido de los panderos, y el trémulo clamor de los pitos, y el estrépito de las sonajas de hoja de lata: la puerta está entornada; sartas de farolillos de papel de diversos colores, arcos de tule y obleas suspendidas en tiras de papel que oscilan a merced del viento, y 'mundos' también de oblea; el patio se mira barrido; en las puertas de los cuartitos linternas y faroles de 'vejiga' y de cristal, el interior de los cuartos limpio y perfumado con alhucema de olor o agua de azahar: blanca y encarrujada la ropa de la cama y el envigado con el amarillo encendido del sacatlascale: de paso lo ve el delicado petimetre componiéndose la corbata, y como queriendo tomar un aire marcial y franco. Sigamos adelante: estoy convidado número, etcétera, por la merced, por el Carmen, calle de Mesones, posadas. [...] Aquí ya no puedo guardar el anónimo, es forzoso que me aparezca yo, el que escribo, con mis mismas señales, a decir lo que vi noches pasadas (PRIETO, 1993, p. 51-52) ${ }^{124}$.

com voz de bassoassoluto: "ao bom coco fresco, amendoim torrado no forno" (PRIETO, 1993, p. 48-49).

${ }^{124}$ Das casas da vila saem cânticos tumultuosos em coro, que se misturam com o barulho dos pandeiros e o tremor do sonido dos apitos, e o estrépito dos chocalhos de folha de metal: a porta está entornada; lanternas de papel penduradas de diversas cores, arcos de tule e obleas penduradas em fitas de papel que oscilam a vontade do vento, e 'mundos' também de oblea; o pátio da para perceber que foi barrido; nas portas dos quartinhos lanternas e faroles de 
O escritor, o "costumbrista" testemunha o que ele olha e percebe; descreve, compara, critica, faz uma leitura da cidade e da sociedade que forma parte dela. Não fica fora dos acontecimentos, precisa estar neles, ser parte deles, para, dessa maneira, falar de questões morais, civis, culturais, politicas e para definir quais tipos de costumes fazem com que o mexicano seja mexicano, o que é parte da sua missão como escritor, pois as coisas e os acontecimentos quotidianos envolvem ao cidadão no seu dia a dia. No caso da literatura mexicana do século XIX, as ideias expostas são as mais importantes para compreender o processo político e social de uma nova nação que, no caso do México, teve na literatura e no escritor a função de criar esse projeto. Agora, qual é o ponto de encontro da missão do escritor com a obra e as ideias de José de Alencar?

Paulo Franchetti, na edição da novela Iracema ${ }^{125}$, vai assinalar que há vários textos essenciais de José de Alencar ${ }^{126}$ para entender qual é a missão do romancista. Os documentos "Como e porque sou romancista?", "Benção paterna" 127 , além de "Resposta a Confederação dos Tamoios"

'bexiga' e de cristal, o interior dos quartos limpo e perfumado com cheiro de lavanda ou agua de flor de laranjeira: branca e encaracolada a roupa de cama e as vigas com a cor amarelo do sacatlascale: ao passo consegue olhar o delicado presunçoso arrumando-se a gravata, e como desejando tomar um ar marcial e franco. Sigamos adiante: estou convidado número, etcétera, pela merced, pelo Carmen, rua de Mesones, posadas [...] Aqui já não posso guardar o anónimo, é preciso que apareça eu, quem está escrevendo, com as minhas mesmas sinais, a dizer o que eu vi as noites passadas (PRIETO, 1993, p. 51-52).

${ }^{125}$ Paulo Franchetti, “Apresentação", en José de Alencar, Iracema. Lenda do Ceará, Brasil, Ateliê Editorial, 2012.

${ }^{126}$ José de Alencar, "Diplomado em Direito", foi deputado (1861) e Ministro de justiça (1868 - 1870), Vai desenvolver uma "novela representativa" das distintas regiões no Brasil no século XIX.

${ }^{127}$ O texto: "Benção paterna", pertence ao prólogo da obra Sonhos de Ouro, publicada no ano de 1872 .

${ }^{128} \mathrm{Na}$ introdução biográfica de Brito Broca, publicada na edição comemorativa do centenário da obra Iracema (1865) de José de Alencar (1829 - 1877), o autor sinala um ponto importante que vai definir a criação dessa novela: o debate que vai ter com Gonçalves Magalhães (1811 1822) nos anos posteriores a 1856. A pugna entre os dois autores vai se dar pela publicação da obra A Confederação dos Tamoios no ano de 1856, na qual, Gonçalves Magalhães vai tentar criar uma gesta épica a partir da ficção da cultura indigena. A edição dessa obra vai dar como resulta uma resposta contundente de José de Alencar, quem, no seu texto nomeado: "Polêmica sobre A Confederação dos Tamoios", vai estabelecer as pautas que vão definir uma "literatura brasileira". Maria Eunice Moreira ao fazer uma descrição da disputa estética entre os dois autores, vai definir a José de Alencar como um leitor: "atento, preparado e conhecedor dos 
vão nos permitir entender as ideias do autor e o relacionamento das mesmas com a categoria desenvolvida.

No texto "Benção paterna", José de Alencar vai desenvolver o que é e representa a literatura nacional:

A literatura nacional que outra é senão a alma da pátria, que transmigrou para este solo virgem com uma raça ilustre, aqui impregnou-se da seiva americana desta terra que lhe serviu de regaço; e cada dia se enriquece ao contato de outros povos e ao influxo da civilização? (ALENCAR, 1977, p. 165).

A literatura nacional ou a alma de uma pátria é a apropriação de um espaço, de um lugar que, na literatura, vai se apresentar como algo que pode se reconhecer, entender, compreender, porém, o leitor ao fazer uma leitura da mesma, dará seu senso próprio, pessoal, além de espiritual. Esse reconhecimento precisa de um processo, de uma evolução histórica na qual o texto literário vai ter varias facetas e momentos para que a mesma seja entendida e compreendida, para ser essa composição espiritual na qual os leitores vão se identificar, e porém, reconhecer o universo que um escritor vai configurar na mesma. Pelo qual, podemos pensar que a literatura, no caso de José de Alencar, cumpre uma missão: a de representar a realidade a partir dos processos históricos que vão se configurar numa obra literária ou num conjunto das mesmas como se elas fossem uma totalidade orgânica que muda numa linha continua e evolutiva:

O período orgânico desta literatura conta já três fases. A primitiva, que se pode chamar aborígine, são as lendas e mitos da terra selvagem e conquistada; são as tradições que embalaram a infância do povo, e ele escutava como o filho a quem a mãe acalenta no berço com as canções, da pátria que abandonou. Iracema pertence a essa literatura primitiva, cheia de santidade e enlevo, para aqueles que veneram na terra da pátria a mãe fecunda - alma mater, e não enxergam nela apenas o chão onde pisam. O segundo período é histórico: representa o consorcio do povo invasor com a terra americana, que dele recebia a cultura, e lhe retribuía

gregos a os contemporâneos". Essa observação serve a autora para definir, mais além da polemica com a obra de Magalhães um novo rumo na conceição estética da literatura brasileira, na qual, Alencar vai formar um projeto nacional. 
nos eflúvios de sua natureza virgem e nas reverberações de um solo esplêndido.[...] A terceira fase, a infância de nossa literatura, começada com a independência política, ainda não terminou; espera escritores que lhe dêem os últimos traços e formem o verdadeiro gosto nacional, fazendo calar as pretensões hoje tão acesas, de nos recolonizarem pela alma e pelo coração, já que não o podem pelo braço (ALENCAR, 1977, p. 165-166).

A referência da obra citada nos permite pensar na literatura da seguinte forma: pela necessidade de deduzir uma composição orgânica, e porém, evolutiva, onde a literatura vai ter uma função política clara ao conformar um projeto de estado. Pelo fato de afirmar que a história é um modelo de conhecimento e de representação que permite definir modelos morais, éticos e de conduta nos personagens literários que tem uma veneração pela "madre patria" e pelo projeto de Estado que está à procura de uma identidade a partir da literatura.

Além dos documentos citados, as cartas nomeadas: "Polêmica sobre A Confederação dos Tamoios" ${ }^{129}$ vão desenvolver uma poética nacional já que nelas José de Alencar vai estabelecer uma relação entre a história da conquista e o descobrimento do Brasil com os indigenas como personagens literários, além de uma proposta poética que tem um ponto de encontro com o texto "Como e porque sou romancista", já que neles a natureza vai formar parte da ficção do autor, desenvolvendo uma perspectiva diferente da mesma e uma transfiguração dela na obra literária onde a historia, as leituras e reflexões vão ser parte de uma epopeia ou gesta de heróis indigenas, que vão ser figuras exemplares ou com características ruins ou brutais por natureza ${ }^{130}$.

O projeto literário de José de Alencar é um sistema de representação da realidade que, a partir da história e do senso evolutivo da

\footnotetext{
129 José de Alencar, "Polêmica sobre A Confederação dos Tamoios", em Domingos José Gonçalves de Magalhães, A Confederação dos Tamoios edição fac-similar seguida da polêmica sobre o poema, Curitiba, Editora Universidade Federal do Paraná, 2007.

130 A poética como estrutura e forma de representação, cumpre um objetivo, o fato de entender e compreender a transcendência espiritual a partir das aciones que os personagens desenvolvem nas obras literárias, além do fato de que as aciones que se configuram na ficção, se transformam em modelos e normas de conduta que revelam um padrão, uma norma e um sentido na ficção literária.
} 
mesma, vai configurar uma totalidade, um corpo, onde a literatura vai se conjugar nos ossos e nos músculos do mesmo, a partir do seu senso transcendente pela representação da mesma na ficção literária. No texto: "Como e porque sou romancista" podemos entender que o romancista vai configurar seu próprio modelo de representação a partir de leituras que vão conformar sua própria poética, como um húmus ${ }^{131}$ que vai nutrir suas ideias, sua concepção da realidade, o senso da ficção literária e da procura de uma identidade e a criação de uma literatura nacional que faz parte de um projeto político. A literatura, no caso de José de Alencar, vai ter relação com o senso evolutivo e com a história como se fosse um acontecimento biológico, orgânico, onde o mito faz parte da lenda e da construção histórica, pela qual a chamada "Missão do escritor" brasileiro é fazer uma representação das questões sociais, históricas e políticas, que ajudem o leitor a entender e conhecer sua realidade e sua identidade.

José de Alencar e Guillermo Prieto vão desenvolver nas suas obras um programa de representação da realidade nacional brasileira, no caso de Alencar; e mexicano, no caso de Guillermo Prieto, nos quais os costumes, a historia, os personagens, vão definir uma identidade pessoal e também uma missão.

A missão do escritor mexicano, no caso de Guillermo Prieto, é que o leitor saiba e conheça qual é sua historia, como são seus costumes, o que faz com que o mexicano seja mexicano no dia a dia e também o que é o que o mexicano do século XIX precisa para ser cidadão numa sociedade que quer ser moderna e por isso o escritor vai representar na literatura todas essas questões ou elementos que o leitor precisa reconhecer; e, no caso de José de Alencar, a missão do escritor brasileiro vai ser criar uma historia, um programa onde a representação do Brasil vai ser um projeto nacional que vai representar não só os costumes da sociedade, senão também a historia, a poética, os indigenas, as diversas regiões que fazem

131 O concepto "humus" vai ser definido por Jorge Puccinelli no prólogo do livro titulado: "Desde Europa" Crónicas y artículos de César Vallejo, no qual vai assinalar duas tarefas importantes para definir um estudo critico: a primeira é a tarefa heuristica, que é a indagação e o descobrimento de fontes históricas; a segunda tarefa será o trabalho filológico, o qual vai considerar a cultura manifestada a través da lingua, focando-senos textos escritos como base e corpo de estudo. Esta conjunção entre o sentido heuristico e o filológico define um ponto importante, o fato de entender, na obra literária e no estudo crítico da mesma, um sentido de unidade quando se refere ao estudo da obra de Vallejo desde una visão critica: "No cabe, pues, tarea hermenéutica firme, sobre todo tratándose de una poesía a veces difícil y hermética, si no se conoce en toda su riqueza al macro texto y el contexto em el que ella se genera, el húmus en que ella germina y, para decirlo com las palabras del poeta, si no se restituye esta flor y este fruto a su natural "eje dialéctico" de crecimiento" (p. VIII). 
com que o Brasil seja uma entidade complexa na sua obra literária. Isso vai definir em José de Alencar e Guillermo Prieto um ponto de encontro com a missão do escritor no Brasil e no México onde a criação de um sistema de representação literária, além de fazer com que o leitor reconheça o seu próprio universo social e político, vai formar nele valores cívicos de um cidadão modelo ou que está na procura de ser assim mesmo nas novas nações latino-americanas do século XIX.

\section{REFERÊNCIAS}

ALENCAR, José de. Polêmica sobre A Confederação dos Tamoios. In: A Confederação dos Tamoios edição fac-similar seguida da polêmica sobre o poema. Org. Maria Eunice Moreira e Luis Bueno. Curitiba: Editora Universidade Federal do Paraná, 2007.

ALENCAR, José de. Como e porque sou romancista. In: O Guarani, Iracema, Ubirajara. A formação da Nacionalidade. Aborigens, V. I. Brasília: Livraria José Olympo Editora. Instituto Nacional do Livro. Ministério da Educação e Cultura, 1977.

ALENCAR, José de. Benção paterna. In: Cinco minutos, A viuvinha, A pata da Gazela, Sonhos de Ouro, Encarnação. Volume 6. Brasília: Livraria José Olympo Editora. Instituto Nacional do Livro. Ministério da Educação e Cultura, 1977.

ARISTÓTELES, Poética. Madrid: Editorial Gredos, (Biblioteca Románica Hispánica, IV. Textos, 8), 1999.

FRANCHETTI, Paulo. Apresentação. In: Iracema. Lenda do Ceará. Org. Leila Guenther. Brasil: Ateliê Editorial, 2012.

LUZÁN, Ignacio de. La poética o reglas de la poesía en general y de sus principales especies (Ediciones de 1737 y1789) con Las Memorias de la vida de Don Ignacio de Luzan escritas por su hijo. Madrid: Ediciones Cátedra, 1974.

MARTÍNEZ, José Luis. La expresión nacional. México: Editorial Oasis, 1984. 
MORA, Pablo. Guillermo Prieto (1818 - 1897). In: La misión del escritor. Ensayos mexicanos del siglo XIX. Ed. Jorge Ruedas de la Serna. México: Universidad Nacional Autónoma de México. Coordinación de Humanidades. Dirección General de Publicaciones, 1996.

ORTEGA Y GASSET, José. La deshumanización del arte. Obras completas. Tomo III Madrid: Alianza Editorial, 1994.

PERALES, OJEDA, Alicia. Las Asociaciones Literarias Mexicanas, Tomos I y II. México: Universidad Nacional Autónoma de México. Coordinación de Humanidades Programa Editorial. Instituto de Investigaciones Filológicas, 2000 .

PICARD, Roger. El romanticismo social. Colección Conmemorativa 70 Aniversario México: Fondo de Cultura Económica, 2005.

PRIETO, Guillermo. Cuadros de costumbres I. México: Consejo Nacional para la Cultura y las Artes, 1993.

PRIETO, Guillermo. Memorias de mis tiempos. México: Consejo Nacional para la Cultura y las Artes, 2005.

PUCCINELLI, Jorge. Prólogo. In: César Vallejo "Desde Europa" Crónicas y artículos (1923 - 1938). Lima: Ediciones Fuente de Cultura Peruana, 1987.

RUEDAS DE LA SERNA, Jorge. La novela corta de la Academia de Letrán. In: La novela corta en el primer romanticismo mexicano. Ed. Celia Miranda Cárabes. México: Coordinación de Humanidades. Instituto de Investigaciones Filológicas, 1998.

RUEDAS DE LA SERNA, Jorge. Presentación. In: La misión del escritor. Ensayos mexicanos del siglo XIX. Ed. Jorge Ruedas de la Serna. México: Universidad Nacional Autónoma de México. Coordinación de Humanidades. Dirección General de Publicaciones, 1996.

RUEDAS DE LA SERNA, Jorge. Cuando pinto no retrato. In: Manuel Payno, Costumbres mexicanas. Obras completas IV. México: Consejo Nacional para la Cultura y las Artes, 1998. 
A missão do escritor e o sistema literário no século XIX:

México (Guillermo Prieto) e o Brasil (José de Alencar) na criação de um estado nacional a partir da literatura | 327

Recebido em: 13/06/2016

Aceito em: 12/07/2016 